\title{
Transfusion Camp: a prospective evaluation of a transfusion education program for multispecialty postgraduate trainees
}

\author{
Yulia Lin, ${ }^{1,2,3,4}$ Everad Tilokee, ${ }^{3,5}$ Sophie Chargé, ${ }^{3,5}$ Asim Alam, ${ }^{3,6}$ Christine Cserti-Gazdewich (1), 2,3,4,7 \\ Wendy Lau, ${ }^{2,3,4,8}$ Christie Lee, ${ }^{3,9}$ Lani Lieberman, ${ }^{1,2,3,4,7}$ Paula Nixon, ${ }^{2,3}$ Wendy Owens, ${ }^{3,10}$ \\ Katerina Pavenski, ${ }^{2,3,4,11}$ Jacob Pendergrast, ${ }^{2,3,4,7}$ Elianna Saidenberg, ${ }^{3,12}$ Nadine Shehata, ${ }^{2,3,4,13}$ \\ Robert Skeate, ${ }^{2,3,4,5}$ Qi-Long Yi, ${ }^{5}$ David Conrad, ${ }^{14}$ Jill Dudebout, ${ }^{15}$ Cyrus C. Hsia, ${ }^{16}$ Michael Murphy, ${ }^{17}$ \\ Oksana Prokopchuk-Gauk, ${ }^{18}$ Akshay Shah, ${ }^{17}$ Ziad Solh, ${ }^{16}$ Jacqueline Trudeau, ${ }^{19}$ Michelle P. Zeller, ${ }^{20,21}$ \\ and Jeannie Callum ${ }^{1,2,3,4}$
}

\begin{abstract}
BACKGROUND: The optimal method of providing transfusion medicine (TM) education has not been determined. Transfusion Camp was established in 2012 at the University of Toronto as a centrally delivered $\mathrm{TM}$ education program for postgraduate trainees. The impact of Transfusion Camp on knowledge, attitudes, and self-reported behavior was evaluated.

METHODS: Didactic lectures (delivered locally, by webinar, or recorded) and locally facilitated team-based learning seminars were delivered over 5 days during the academic year to 8 sites: 7 in Canada and 1 in the United Kingdom. Knowledge assessment using a validated 20-question multiple-choice exam was conducted before and after Transfusion Camp. Attitudes and self-reported behavior were collected through a survey.
\end{abstract}

RESULTS: Over 2 academic years (July 2016 to June 2018), 390 trainees from 16 different specialties (predominantly anesthesia, $41 \%$; hematology, $14 \%$; and critical care, $7 \%$ ) attended at least 1 day of Transfusion Camp. The mean pretest score was 10.3 of $20( \pm 2.9$; $\mathrm{n}=286)$ compared with posttest score of $13.0( \pm 2.8$; $\mathrm{n}=194 ; \mathrm{p}<0.0001)$. Lower pretest score and greater attendance (4-5 days compared with 1-3 days) were associated with larger improvement in posttest score; delivery format, specialty, and postgraduate year were not. Trainees reported an improvement in self-rated abilities to manage TM scenarios; 95\% rated TM knowledge as very or extremely important in providing patient care; and $81 \%$ indicated that they had applied learning from Transfusion Camp into clinical practice. CONCLUSIONS: Transfusion Camp increased TM knowledge, fostered a positive attitude toward TM, and enabled a self-reported positive impact on transfusion practice in postgraduate trainees. It is a novel and scalable approach to delivering TM education.
ABBREVIATIONS: $\mathrm{PGY}=$ postgraduate year; $\mathrm{TBL}$ = team-based learning; $\mathrm{TM}=$ transfusion medicine.

From the ${ }^{1}$ Department of Laboratory Medicine and Molecular Diagnostics, Sunnybrook Health Sciences Centre, the ${ }^{2}$ Department of Laboratory Medicine and Pathobiology, and the ${ }^{9}$ Interdepartmental Division of Critical Care Medicine, Department of Medicine, University of Toronto, the ${ }^{3}$ University of Toronto Transfusion Camp Planning Committee, the ${ }^{4}$ University of Toronto Quality in Utilization, Education and Safety in Transfusion (QUEST) Research Program, the ${ }^{6}$ Department of Anesthesia, North York General Hospital, the ${ }^{7}$ Laboratory Medicine Program, University Health Network, the ${ }^{8}$ Department of Paediatric Laboratory Medicine, The Hospital for Sick Children, the ${ }^{11}$ St. Michael's Hospital, the ${ }^{13}$ Department of Medicine, Division of Hematology, Mount Sinai Hospital, Toronto, the ${ }^{5}$ Medical Affairs and Innovation, Canadian Blood Services, the ${ }^{12}$ Hematology and Transfusion Medicine, The Ottawa Hospital, Ottawa, the ${ }^{14}$ Division of Hematopathology, Dalhousie University \& Nova Scotia Health Authority Central Zone, Halifax, the ${ }^{15}$ Queen's University, Kingston, the ${ }^{16}$ Department of Pathology \& Laboratory Medicine, Schulich School of Medicine \& Dentistry, Western University, London, the ${ }^{18}$ Department of Pathology and Laboratory Medicine, University of Saskatchewan, Saskatoon, the ${ }^{19}$ Department of Anesthesiology, Pharmacology and Therapeutics, University of British Columbia, Vancouver, the ${ }^{20} \mathrm{McMaster}$ Centre for Transfusion Research, McMaster University, Hamilton, the ${ }^{21}$ Canadian Blood Services, Ancaster, and the ${ }^{10}$ Ontario Regional Blood Coordinating Network, Ontario, Canada; and the ${ }^{17}$ Oxford University Hospitals, Oxford, United Kingdom.

Address reprint requests to: Yulia Lin, Department of Laboratory Medicine and Molecular Diagnostics, Sunnybrook Health Sciences Centre and University of Toronto, 2075 Bayview Avenue, Room B2-04, Toronto, Ontario, M4N 3M5, Canada; e-mail: yulia.lin@sunnybrook.ca.

Financial support for the University of Toronto site was provided by the Ontario Regional Blood Coordinating Network, the University of Toronto Department of Laboratory Medicine and Pathobiology and in 2016-2017, partially by two unrestricted educational grants from CSL Behring and Grifols. Financial support for the University of British Columbia site in 2017-2018 was provided by the British Columbia Provincial Blood Coordinating Office, the UBC Centre for Blood Research and grants from Grifols, Octapharma and Bayer.

Received for publication December 17, 2018; revision received January 25, 2019, and accepted February 9, 2019.

doi:10.1111/trf.15284

(C) 2019 AABB

TRANSFUSION 2019;9999;1-9 
B lood transfusion is the most common procedure administered in hospitalized patients and is prescribed by physicians of almost every specialty. ${ }^{1,2}$ Despite advances in recent decades, transfusion remains an intervention associated with risk. Expert panels have recommended strategies to reduce mortality and morbidity related to transfusion, including adherence to evidence-based transfusion guidelines and increased transfusion medicine (TM) education. ${ }^{3}$ One of the challenges in delivering TM education is determining the optimal time in training to deliver such content. Recent reviews advocate for TM education at the beginning of clinical training, either in medical school or early in the postgraduate training period, so as to tailor to the specialty. ${ }^{4-6}$ However, several studies have shown that TM knowledge at this level is deficient. ${ }^{7-12}$ Additional challenges include reaching trainees in multiple specialties and limited faculty to deliver TM education.

Transfusion Camp was developed at the University of Toronto in 2012 to meet increasing demands for postgraduate TM education. ${ }^{13}$ Prior to Transfusion Camp, 1-month blood bank rotations were offered to trainees in anesthesia, critical care, hematology, and/or hematopathology at three academic hospitals in Toronto. These blood bank rotations were limited to a maximum of three trainees per rotation, and faculty were obliged to repeat the curriculum monthly. Transfusion Camp was initiated as a centralized TM education program to meet the needs of University of Toronto trainees and to more efficiently leverage the expertise of the TM faculty across five University of Toronto hospitals and the local blood operator, Canadian Blood Services. In collaboration with the Centre for Innovation at Canadian Blood Services, the Ontario Regional Blood Coordinating Network, and university site transfusion leads, Transfusion Camp was expanded to include eight university sites by 2017-2018.

The aim of this report is to evaluate the impact of the Transfusion Camp education program on postgraduate trainee knowledge, attitudes, and self-reported behavior.

\section{METHODS}

\section{Educational program}

Transfusion Camp will be described according to Thomas and Kern's approach to curriculum development in medical education. ${ }^{6,14}$ The target audience is non-hematology specialtybased postgraduate trainees, although postgraduate trainees from hematology and hematopathology are also encouraged to attend. The goal of Transfusion Camp is to provide postgraduate trainees with practical, essential, and evidence-based TM knowledge. Specific learning objectives (Table 1) were developed using expert opinion, literature review, and an underlying theoretical structure of relevant domains. A formal needs assessment was not performed. Educational process objectives were 1) at least $80 \%$ of trainees rate speakers as good or excellent based on five criteria: objectives of presentation defined
TABLE 1. Learning objectives of Transfusion Camp

Indications for blood products

1. Appropriately prescribe components (RBC, plasma, platelets, and cryoprecipitate).

2. Perform a preoperative bleeding history.

3. Interpret coagulation testing results.

4. Have a reasonable approach to the correction of coagulation prior to procedures.

Blood bank testing

5. Summarize basics about blood bank tests and pretransfusion compatibility testing.

6. Explain the implications of a positive antibody screen.

7. Know when to screen patients for platelet alloimmunization.

Risks of transfusion

8. Obtain informed consent for transfusion.

9. Prevent, diagnose, manage, and report acute and delayed transfusion reactions.

10. State the current risks of transfusion-transmitted infections.

11. Describe challenges to transfusion safety (getting the right blood to the right patient).

Indications for manufactured blood products

12. Appropriately prescribe fractionated blood products (albumin, coagulation factor concentrates).

13. State when and how Rh immunoglobulin is administered in pregnancy.

Special transfusion situations

14. Develop an approach to patients with congenital or acquired bleeding disorders (including reversal of common anticoagulants)

15. Safely transfuse a patient with sickle cell disease.

16. Manage a massively hemorrhaging patient, including surgical, trauma, and obstetric patients, with discussion of hemostatic medications (antifibrinolytics).

Blood conservation

17. Have a standard approach to the management of preoperative anemia.

18. Apply patient blood management strategies, including for patients who refuse blood on religious grounds.

and met, practical value, knowledge of topic, presentation skills, and balanced and unbiased; and 2) at least $80 \%$ of trainees agree or strongly agree that the seminar content has practical value and that the seminar content is relevant and organized. The $80 \%$ cutoff was determined by consensus.

The program occurs over 5 themed days (Table 2). For each half-day, two to three large-group didactic lectures are followed by small-group modified team-based learning (TBL) seminars. With the expansion to external sites, didactic

TABLE 2. Transfusion Camp educational program and theme for each day

\begin{tabular}{|c|c|c|}
\hline Day & Month & Theme \\
\hline 1 & July & $\begin{array}{l}\text { Pre-Camp test } \\
\text { Indications for blood components }\end{array}$ \\
\hline 2 & September & Transfusion reactions \\
\hline 3 & January & $\begin{array}{l}\text { Special transfusion situations: maternal, } \\
\text { perioperative bleeding assessment, } \\
\text { sickle cell disease }\end{array}$ \\
\hline 4 & April & $\begin{array}{l}\text { Perioperative patient blood management, } \\
\text { congenital and acquired hemostasis } \\
\text { disorders }\end{array}$ \\
\hline 5 & June & $\begin{array}{l}\text { Trauma, massive hemorrhage protocols } \\
\text { Post-Camp test }\end{array}$ \\
\hline
\end{tabular}


lectures delivered locally in Toronto were broadcast live by webinar (GoToWebinar) to six external Canadian university sites (Dalhousie University, McMaster University, Queen's University, University of Ottawa, University of Saskatchewan starting in 2016-2017, and Western University in 2017-2018). To accommodate time differences, the didactic lectures were recorded and viewed later in group sessions for University of British Columbia trainees or individually by Oxford University Hospital trainees in the United Kingdom. At all sites, the modified TBL case-based seminars were led in person by local faculty to groups of 5 to 15 trainees with a seminar moderator guide developed by University of Toronto faculty.

TBL is an active learning and small-group instructional strategy that provides students with opportunities to apply conceptual knowledge and has been shown to increase learner engagement. ${ }^{15}$ Because of time constraints, a modified TBL structure was used in Transfusion Camp seminars. TBL seminar content was developed using cases constructed by content experts followed by a series of multiple-choice questions. Trainees were given cards labeled A, B, C, and D and were asked to choose and display their answers simultaneously. Facilitators would then ask trainees to provide justification for their answer. Once each of the proposed answers had been considered, a brief summary of the discussion and other relevant points was given by the facilitator. Facilitators collected and reviewed the tally of the trainee responses and adjusted questions for the following year's seminar. Trainees from different specialties were deliberately intermingled within the seminar groups to provide additional perspectives on each case.

Transfusion Camp was coordinated by the University of Toronto Transfusion Camp Planning Committee with representation from transfusion, hematology, anesthesia, critical care medicine, and Canadian Blood Services. This committee developed the educational program, determined the objectives, reviewed the evaluations, and adjusted the curriculum accordingly. The committee met within the month after each Transfusion Camp day to review feedback and make curriculum changes for the next program day. The entire curriculum was reviewed at least once annually. The funding for Transfusion Camp from the Ontario Regional Blood Coordinating Network included funding to expand to all Ontario universities, and thus these universities were specifically approached by the Planning Committee. For all other sites outside Ontario, the sites voluntarily approached the Planning Committee to participate in Transfusion Camp. To support implementation of Transfusion Camp across multiple sites, a local physician and administrative lead were identified at each site. The local physician lead was responsible for connecting with program directors, inviting trainees to Transfusion Camp, and engaging local faculty to facilitate seminars. In most cases, program directors agreed to have their trainees participate. A minority of program directors declined to have their trainees participate because of the time commitment for all 5 days; some programs attended for selected days of Transfusion Camp. Given the number of sites and programs, there was variation in whether trainee participation was mandatory or voluntary. If mandatory, protected time and release from clinical duties was provided for trainees to participate. If voluntary, it was up to trainees to negotiate time to participate in Transfusion Camp. The local administrative lead booked rooms and catering, arranged the audiovisual connection, tracked trainee attendance, and administered exams. Canadian Blood Services provided national administrative oversight and the technology infrastructure for a collaborative environment. A Web-based tool (SurveyMonkey: http://www. surveymonkey.com) was used to register trainees and collect evaluations on educational process outcomes. A Web-based collaborative platform (Sharepoint, Microsoft) was established to house educational material, including journal article prereading, didactic lectures, seminar material, and videos of recorded didactic lectures that were made available to all trainees. In addition, the platform provided an administrative subsection for faculty, administrative leads, and Planning Committee members to share resources and track attendance. No cost was charged to participating sites.

\section{Outcome measures}

The 2 academic years reviewed were from July 2016 to June 2018. Research ethics board approval was obtained from the University of Toronto. Research ethics board approval at the other participating sites was waived by the individual research ethics boards because the project involved evaluation of an education program. Registration records provided trainee characteristics including postgraduate year (PGY) level, specialty, and university. Attendance records provided trainee attendance for each of the 5 days. Trainees were included if they attended at least 1 of 5 days of Transfusion Camp.

The impact of Transfusion Camp was assessed in three main domains: knowledge, attitudes, and self-reported impact on behavior. The primary outcome measure was knowledge gain, defined as the change in exam score from before to after Transfusion Camp using a validated 20-question multiplechoice exam developed by the Biomedical Excellence for Safer Transfusion collaborative. ${ }^{16}$ The same exam was used before and after Transfusion Camp. Trainees were not provided with either the test questions or answers after the exam but did receive their scores 2 to 3 months after Transfusion Camp. The score difference (posttest score minus pretest score for trainees who had written both tests) was compared according to delivery format, trainee specialty, year of training (PGY), attendance, and selfrated knowledge. For each question, the percentage of trainees answering correctly was also examined.

Secondary outcome measures were trainee attitudes toward TM and self-reported impact on transfusion behavior, assessed through post-Transfusion Camp surveys. Metrics included percentage of respondents rating their abilities in managing nine different TM activities as good, very good, or excellent; rating TM knowledge as very or extremely important in providing care to patients in their practice; and reporting the impact of Transfusion Camp on their clinical practice. In addition, feedback from 
faculty and program directors was collected via informal communications and surveys, including opinions on the format change from traditional to TBL-based seminars.

As the exam was originally validated as a knowledge assessment tool in 2012, a repeat Rasch analysis was performed on the 2016-2017 pre- and posttest results to ensure that questions still had reliability and question fit (Winsteps: http://www.winsteps.com). This psychometric approach compares exam results to those predicted by the model based on question difficulty and examinee ability. ${ }^{16,17}$ Exam quality was determined by calculating the "fit" of each question with the model with an ideal score of 1.00. Questions with a fit value of more than 1.50 have more variance than expected and should be reevaluated. Both the pretest and posttest results in 2016-2017 had high reliability (0.97 and 0.95, respectively) and good mean fit (1.00 and 0.96 , respectively), supporting its ongoing validity in knowledge assessment.

\section{Statistical analysis}

Continuous variables were described using means with standard deviation (normality check found both pretest and posttest scores were symmetrically distributed with close to normal distribution), and categorical variables were described using frequency and proportion. The exam score difference (posttest score minus pretest score) was calculated only for trainees who had written both tests to represent knowledge gain from training. The association between each of the trainee characteristics and score difference was tested using analysis of variance. Modeling analysis was performed to find the adjusted effect of trainee characteristics on the score difference. In the model, the score difference was the outcome variable, and the potential predictors were pretest score, delivery format (local vs. remote live vs. recorded sessions), attendance (4-5 days vs. 1-3 days), PGY level (1 vs. $2-3$ vs. $4+$ ) and specialty (anesthesia vs. hematology vs. critical care medicine vs. others). A p value of less than 0.05 was used to denote statistical significance. All analyses were run using computer software (SAS Version 9.3, SAS Institute).

\section{RESULTS}

\section{Postgraduate trainees}

Over 2 academic years, 390 postgraduate trainees attended at least 1 day of Transfusion Camp (Table 3). A mean of 113 trainees attended each day (range, 97-132) in 2016-2017, increasing to 144 (range, 120-180) in 2017-2018. The number of trainees who participated in Transfusion Camp at each university site ranged from 6 to 58, with the largest group being from the University of Toronto (29\%). Trainees from 16 different specialty programs were represented, with the top 3 specialties being anesthesia (41\%), hematology (14\%), and critical care medicine (7\%) (Table 3).

Responses to pre-Transfusion Camp questions on previous training and self-perceived ability in TM were available for

\begin{tabular}{|c|c|c|c|}
\hline \multicolumn{4}{|c|}{$\begin{array}{l}\text { TABLE 3. Characteristics of the Transfusion Camp } \\
\text { trainees }\end{array}$} \\
\hline Characteristic & $\begin{array}{c}2016-2017 \\
n=160\end{array}$ & $\begin{array}{c}2017-2018 \\
n=230\end{array}$ & $\begin{array}{c}\text { Total } \\
\mathrm{n}=390\end{array}$ \\
\hline \multicolumn{4}{|l|}{ Specialty, n (\%) } \\
\hline Anesthesia & $68(43)$ & $92(40)$ & $160(41)$ \\
\hline Hematology & $26(16)$ & $30(13)$ & $56(14)$ \\
\hline Critical care medicine & $11(7)$ & $17(7)$ & $28(7)$ \\
\hline $\begin{array}{l}\text { Pediatrics / pediatric } \\
\text { hematology oncology }\end{array}$ & $8(5)$ & $17(7)$ & $25(6)$ \\
\hline $\begin{array}{l}\text { General pathology/ } \\
\text { pathology }\end{array}$ & $18(11)$ & $4(2)$ & $22(6)$ \\
\hline Hematopathology & $7(4)$ & $12(5)$ & $19(5)$ \\
\hline Obstetrics & $11(7)$ & $7(3)$ & $18(5)$ \\
\hline Emergency medicine & $4(3)$ & $12(5)$ & $16(4)$ \\
\hline Surgery* & $0(0)$ & $15(7)$ & $15(4)$ \\
\hline Medical oncology & 5 (3) & $5(2)$ & $10(3)$ \\
\hline Internal medicine & $1(1)$ & $9(4)$ & $10(3)$ \\
\hline Radiation oncology & $0(0)$ & $9(4)$ & $9(2)$ \\
\hline Transfusion medicine & $1(1)$ & $1(1)$ & $2(1)$ \\
\hline \multicolumn{4}{|l|}{ Postgraduate year (n, \%) } \\
\hline 1 & $43(27)$ & $54(24)$ & $97(25)$ \\
\hline 2 & $22(14)$ & 39 (17) & $61(16)$ \\
\hline 3 & $27(17)$ & $41(18)$ & $68(17)$ \\
\hline 4 & $28(18)$ & $56(24)$ & $84(22)$ \\
\hline 5 & $11(7)$ & $17(7)$ & $28(7)$ \\
\hline 6 or higher & $29(18)$ & $23(10)$ & 52 (13) \\
\hline \multicolumn{4}{|l|}{ Attendance by day, n (\%) } \\
\hline Day 1 & $132(83)$ & $180(78)$ & $312(80)$ \\
\hline Day 2 & $125(78)$ & $154(67)$ & $279(72)$ \\
\hline Day 3 & $112(70)$ & $141(61)$ & $253(65)$ \\
\hline Day 4 & $97(61)$ & $124(54)$ & $221(57)$ \\
\hline Day 5 & $98(61)$ & $120(52)$ & $218(56)$ \\
\hline \multicolumn{4}{|c|}{ Number of days attended, $\mathrm{n}(\%)$} \\
\hline 1 day & $17(11)$ & $31(14)$ & $48(12)$ \\
\hline 2 of 5 days & $30(19)$ & $56(24)$ & $86(22)$ \\
\hline 3 of 5 days & 19 (12) & $44(19)$ & $63(16)$ \\
\hline 4 of 5 days & $40(25)$ & $51(22)$ & $91(23)$ \\
\hline All 5 days & $54(34)$ & $48(21)$ & $102(26)$ \\
\hline $\begin{array}{l}\text { * Surgery included gene } \\
\text { urology. }\end{array}$ & surgery, $g$ & cology, or & ogy, and \\
\hline
\end{tabular}

only 2017-2018 trainees $(\mathrm{n}=158)$. Trainees reported zero (20\%), 1 to 2 (49\%), or 3 or more hours (30\%) of TM education in medical school. Seventy-three percent stated that their medical school TM education was not at all or slightly helpful. They rated their knowledge as no knowledge/beginner (60\%), intermediate (39\%), or advanced/expert (1\%).

\section{Knowledge}

\section{Pre-transfusion camp exam scores}

Exam scores were similar for 2016-2017 and 2017-2018 and thus were combined for the analysis. The mean score on the pretest was 10.3 out of 20 (SD 2.9; $\mathrm{n}=286$ ) with variability observed among the specialties (Fig. 1). Better pretest scores were associated with higher self-rated TM knowledge, higher self-rated overall ability in managing TM patient issues, hematology specialty, and increasing PGY level (Table 4). Pretest scores were not associated with number of hours of TM education in medical school or postgraduate university site (data not shown). 


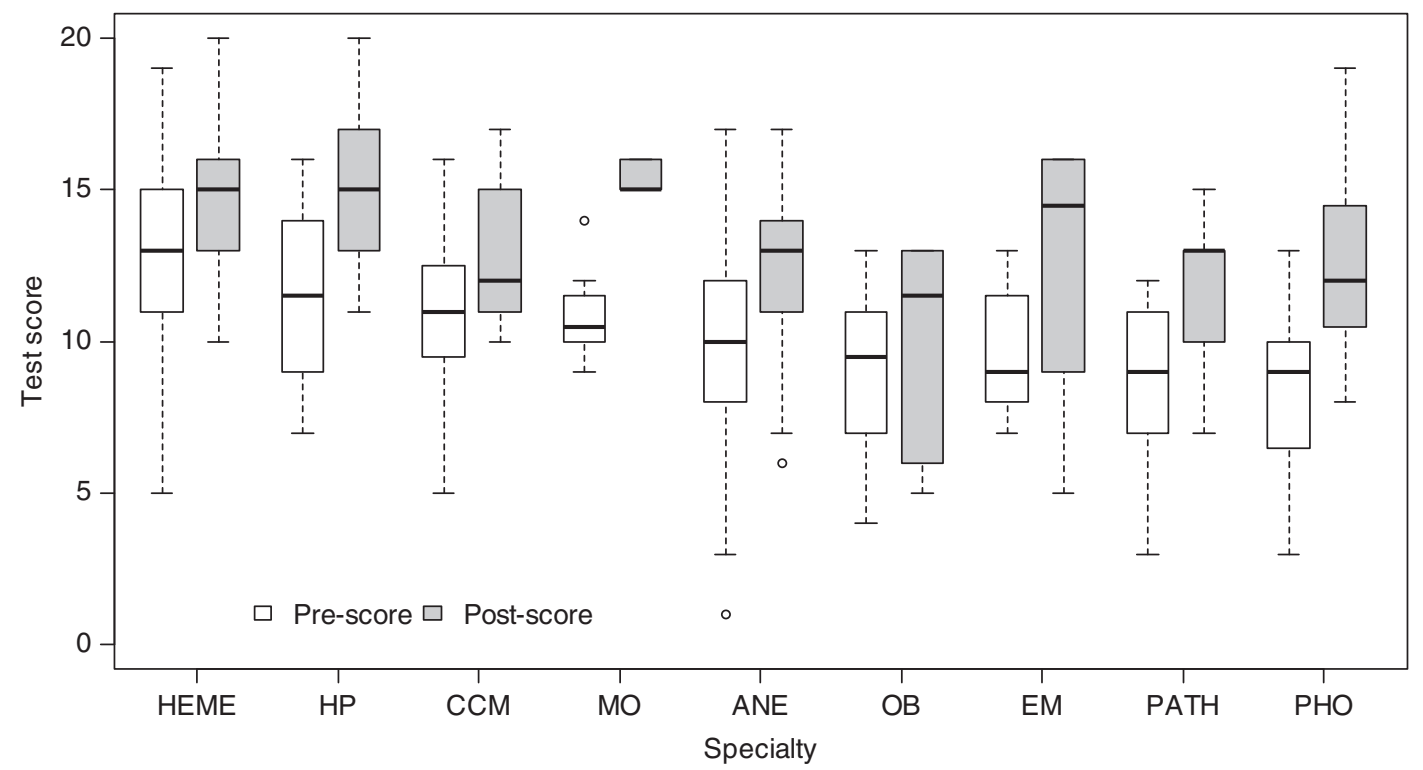

Fig. 1. Pre- and posttest median scores by specialty. Pretest scores $(n=285)$ and posttest scores $(n=195)$. The box plot shows the interquartile range. The whiskers show the maximum and minimum scores for each group. Specialties are listed (pre/post $n$ ): HEME = hematology $(n=42 / 31) ; \mathrm{HP}=$ hematopathology $(\mathrm{n}=15 / 9) ; \mathrm{CCM}=$ critical care medicine $(\mathrm{n}=\mathbf{2 4} / 14) ; \mathrm{MO}=$ medical oncology $(n=8 / 5) ;$ ANE = anesthesia $(n=125 / 98) ;$ OB = obstetrics $(n=14 / 7) ;$ EM = emergency medicine $(n=11 / 4) ;$ PATH = general pathology/pathology $(n=14 / 9) ;$ PHO = pediatrics/pediatric hematology oncology $(n=12 / 12)$. Specialties with 2 or fewer posttest results were excluded from this figure (internal medicine, radiation oncology, surgery, and transfusion medicine).

\section{Improvement in exam scores}

The mean score on the post-Transfusion Camp exam was 13.0 (standard deviation [SD], 2.8; $\mathrm{n}=194$ ). The mean improvement was 2.7 points (of 20$)(\mathrm{p}<0.0001 ; 95 \%$ confidence interval,

\begin{tabular}{|c|c|c|c|}
\hline \multicolumn{4}{|c|}{ TABLE 4. Pretest exam scores } \\
\hline Trainee characteristic & $\mathrm{n}(\%)$ & $\begin{array}{l}\text { Pretest score, } \\
\text { mean (SD) }\end{array}$ & $\mathrm{p}$ value \\
\hline All trainees & $286(100)$ & $10.3(2.9)$ & \\
\hline $\begin{array}{l}\text { Hours of TM education } \\
\text { in medical school* }\end{array}$ & & & NS \\
\hline None & $32(20)$ & $9.9(2.7)$ & \\
\hline $1-2$ hours & $78(49)$ & $10.6(3.0)$ & \\
\hline $3-4+$ hours & $48(30)$ & $10.2(3.1)$ & \\
\hline Self-rated TM knowledge* & & & 0.0001 \\
\hline No knowledge/beginner & $94(60)$ & $10.0(2.6)$ & \\
\hline Intermediate & $61(39)$ & $10.6(3.0)$ & \\
\hline Advanced/expert & $2(1)$ & $18.5(0.7)$ & \\
\hline Self-rated ability to manage & & & 0.02 \\
\hline Poor/fair & $109(37)$ & $10.0(2.5)$ & \\
\hline Good/very good/excellent & 49 (63) & $11.2(3.6)$ & \\
\hline Specialty & & & $<0.0001$ \\
\hline Nonhematology & 42 & $9.9(2.7)$ & \\
\hline Hematology & 244 & $12.5(2.9)$ & \\
\hline Postgraduate year & & & $<0.0001$ \\
\hline 1 & 80 & $9.1(2.9)$ & \\
\hline 2 & 44 & $9.5(2.2)$ & \\
\hline 3 & 45 & $10.7(2.5)$ & \\
\hline 4 & 58 & $11.3(2.8)$ & \\
\hline 5 & 18 & $11.9(3.3)$ & \\
\hline $6+$ & 41 & $10.6(3.0)$ & \\
\hline
\end{tabular}

2.2-3.2). Posttest self-rated TM knowledge was associated with posttest scores: no knowledge/beginner 11.6 (SD, 2.7) vs. intermediate 12.8 (SD, 2.6) vs. advanced/expert 14.6 (SD, 2.9) $(\mathrm{p}=0.0001)$. Of the 159 trainees who wrote both the pre- and posttest, $79 \%$ improved their scores (mean + 3.4; SD, 1.8), $10 \%$ had no change, and $11 \%$ had worse scores (mean - 1.0; SD 1.4). Table 5 shows the association of factors with an improvement in exam score: only attendance of 4 or 5 days appeared to be associated with improvement in scores. In a multivariate analysis, after adjusting for delivery format, specialty, and PGY level, the only factors predicting improvement in scores were lower pretest score (estimate +0.44 of improvement for every 1.0 lower in pretest score; standard error, 0.07 ; $<$ 0.0001) and attendance of 4 or 5 days (estimate +1.23 of improvement compared with $1-3$ days; standard error, $0.57 ; \mathrm{p}=0.03$ ).

\section{Scores by question topic}

Exam question scores were examined individually for improvement (Table 6). In general, trainees' scores improved on questions on indications for transfusion, while there remained difficulties with questions about transfusion reactions. Results were similar when restricted to trainees who wrote both the pre- and posttest. Two questions on the posttest had scores both below $50 \%$ and with improvement less than $10 \%$. The first question focused on postoperative platelet transfusion thresholds for a hemodynamically stable patient immediately after a small bowel resection with bloody drains. Forty-one percent selected the correct response, which was to transfuse at a platelet count less than $50 \times 10^{9} / \mathrm{L}$. However, $55 \%$ chose 


\begin{tabular}{|lccc|}
\hline \multicolumn{4}{|c|}{ TABLE 5. Improvement in exam score } \\
\hline Characteristic & $\mathrm{n}$ & $\begin{array}{c}\text { Mean } \\
\text { difference (SD) }\end{array}$ & p value \\
\hline Delivery format & & & $\mathrm{NS}$ \\
$\quad$ Local & 63 & $2.9(2.5)$ & \\
Remote live & 48 & $2.0(2.2)$ & \\
Recorded & 56 & $2.4(2.8)$ & 0.006 \\
Attendance & & & \\
1-3 days & 19 & $1.0(2.7)$ & NS \\
4-5 days & 148 & $2.7(2.4)$ & \\
Specialty & & & \\
Anesthesia & 88 & $2.6(2.7)$ & \\
Critical care medicine & 12 & $2.2(2.2)$ & \\
Hematology & 29 & $2.2(2.9)$ & \\
Others & 38 & $2.6(2.3)$ & \\
Postgraduate year & & & \\
1 & 59 & $2.8(2.6)$ & \\
2-3 & 47 & $2.3(2.5)$ & \\
4+ & 61 & $2.4(2.5)$ & \\
\hline NS $=$ not significant; SD = standard deviation. & \\
& & & \\
\hline
\end{tabular}

more restrictive thresholds: $11 \%$ at $30 \times 10^{9} / \mathrm{L}$ and $44 \%$ at $10 \times$ $10^{9} / \mathrm{L}$. The second question was on the decision for RBC transfusion in a patient whose only symptom was reduced

\begin{tabular}{|c|c|c|c|c|}
\hline \multicolumn{5}{|c|}{$\begin{array}{l}\text { TABLE 6. Percent correct for individual exam } \\
\text { questions (ranked by post-test percent correct) }\end{array}$} \\
\hline Question topic & $\begin{array}{l}\text { Pre-test } \\
\mathrm{n}=284^{*}\end{array}$ & $\begin{array}{l}\text { Posttest } \\
\mathrm{n}=192^{\dagger}\end{array}$ & $\begin{array}{l}\text { Change } \\
\text { in score } \\
\text { (post-pre) }\end{array}$ & $p$ value \\
\hline $\begin{array}{l}\text { RBC transfusion } \\
\text { (blood loss) }\end{array}$ & $95 \%$ & $98 \%$ & $3 \%$ & NS \\
\hline $\begin{array}{l}\text { RBC transfusion } \\
\text { (prophylaxis) }\end{array}$ & $87 \%$ & $94 \%$ & $7 \%$ & NS \\
\hline $\begin{array}{l}\text { PLT transfusion } \\
\text { (procedure) }\end{array}$ & $83 \%$ & $94 \%$ & $11 \%$ & 0.03 \\
\hline Irradiation & $75 \%$ & $89 \%$ & $14 \%$ & 0.003 \\
\hline $\begin{array}{l}\text { Septic transfusion } \\
\text { reaction }\end{array}$ & $50 \%$ & $89 \%$ & $39 \%$ & $<0.0001$ \\
\hline AHTR (cause) & $74 \%$ & $87 \%$ & $13 \%$ & 0.001 \\
\hline $\begin{array}{l}\text { PLT transfusion } \\
\text { (prophylaxis) }\end{array}$ & $73 \%$ & $81 \%$ & $8 \%$ & NS \\
\hline $\begin{array}{l}\text { AHTR (clinical } \\
\text { presentation) }\end{array}$ & $77 \%$ & $78 \%$ & $1 \%$ & NS \\
\hline Plasma (procedure) & $54 \%$ & $77 \%$ & $23 \%$ & $<0.0001$ \\
\hline Reaction reporting & $50 \%$ & $67 \%$ & $17 \%$ & 0.002 \\
\hline Warfarin reversal & $38 \%$ & $63 \%$ & $25 \%$ & $<0.0001$ \\
\hline TACO & $46 \%$ & $61 \%$ & $15 \%$ & 0.005 \\
\hline Infectious disease risk & $50 \%$ & $57 \%$ & $7 \%$ & NS \\
\hline TRALI reporting & $24 \%$ & $48 \%$ & $24 \%$ & $<0.0001$ \\
\hline TRALI prevention & $25 \%$ & $48 \%$ & $23 \%$ & $<0.0001$ \\
\hline Massive transfusion & $31 \%$ & $47 \%$ & $16 \%$ & 0.03 \\
\hline PLT transfusion (postop) & $40 \%$ & $41 \%$ & $1 \%$ & NS \\
\hline Allergic & $21 \%$ & $31 \%$ & $10 \%$ & 0.008 \\
\hline TRALI reaction & $16 \%$ & $29 \%$ & $13 \%$ & 0.003 \\
\hline $\begin{array}{r}\text { RBC transfusion } \\
\text { (symptomatic) }\end{array}$ & $20 \%$ & $17 \%$ & $-3 \%$ & NS \\
\hline $\begin{array}{l}* \text { The number of train } \\
\text { ranged from } 284 \text { to } 286 \\
+ \text { The number of traine } \\
\text { ranged from } 192 \text { to } 195 \\
\text { AHTR = acute hemolytic } \\
\text { cant; PLT = platelet; TA } \\
\text { overload; TRALI = transf }\end{array}$ & $\begin{array}{l}\text { ees answ } \\
6 . \\
\text { ees answe } \\
\text { transfusic } \\
\text { CO = tran } \\
\text { usion-relate }\end{array}$ & $\begin{array}{l}\text { ering eac } \\
\text { ering each } \\
\text { on reactio } \\
\text { sfusion-as } \\
\text { ed acute lu }\end{array}$ & $\begin{array}{l}\text { phetest } \\
\text { posttest } \\
\text { ins = no } \\
\text { sociated ci } \\
\text { ung injury. }\end{array}$ & $\begin{array}{l}\text { question } \\
\text { question } \\
\text { ot signifi- } \\
\text { irculatory }\end{array}$ \\
\hline
\end{tabular}

TABLE 7. Trainees' self-rated ability in TM-related activities

\begin{tabular}{lccc}
\hline $\begin{array}{l}\text { TM activity rated as good/ } \\
\text { very good/excellent }\end{array}$ & $\begin{array}{c}\text { Pre-test } \\
\mathrm{n}(\%)\end{array}$ & $\begin{array}{c}\text { Post-test } \\
\mathrm{n}(\%)\end{array}$ & $\mathrm{p}$ value \\
\hline $\begin{array}{l}\text { Assessing need for } \\
\quad \text { RBC transfusion }\end{array}$ & $123(78)$ & $186(98)$ & $<0.001$ \\
$\begin{array}{l}\text { Assessing need for } \\
\text { platelet transfusion } \\
\text { Assessing need for } \\
\quad \text { plasma transfusion }\end{array}$ & $84(53)$ & $169(89)$ & $<0.001$ \\
$\begin{array}{l}\text { Assessing need for } \\
\text { cryoprecipitate transfusion }\end{array}$ & $48(30)$ & $150(79)$ & $<0.001$ \\
$\begin{array}{l}\text { Assessing fever } \\
\text { during transfusion }\end{array}$ & $50(32)$ & $158(83)$ & $<0.001$ \\
$\begin{array}{l}\text { Assessing dyspnea } \\
\text { during transfusion }\end{array}$ & $52(33)$ & $164(86)$ & $<0.001$ \\
$\begin{array}{l}\text { Interpreting results of } \\
\text { blood bank testing }\end{array}$ & $51(33)$ & $156(82)$ & $<0.001$ \\
$\begin{array}{l}\text { Obtaining consent } \\
\text { for transfusion }\end{array}$ & $100(63)$ & $180(95)$ & $<0.001$ \\
$\begin{array}{l}\text { Overall ability in managing } \\
\text { TM related patient issues }\end{array}$ & $49(31)$ & $156(82)$ & $<0.001$ \\
$\begin{array}{l}\text { Transfusion medicine (TM) activity was rated on a 5-point Likert } \\
\text { scale (poor, fair, good, very good, excellent). }\end{array}$ & \\
\hline
\end{tabular}

cognition (patient not oriented compared to baseline) rather than a physical symptom (e.g., dyspnea, chest pain). Seventeen percent selected the correct answer to transfuse one unit over 3 hours, while $77 \%$ selected the more restrictive response of "do not transfuse."

\section{Attitudes toward TM and self-reported impact on behavior}

At the end of Transfusion Camp ( $n=190)$, 95\% rated TM knowledge as very or extremely important in providing care to patients in their practice (compared to $83 \%$ precamp; $\mathrm{p}<0.001$ ). Trainees reported an improvement in self-rated abilities to manage nine different TM activities (Table 7). On the survey conducted at the end of Transfusion Camp, 81\% of trainees reported that they had applied learning from Transfusion Camp into clinical practice $(\mathrm{n}=54$ for 2016-2017; $\mathrm{n}=37$ for 2017-2018). Free text examples of applied learning provided by trainees included minimizing unnecessary transfusion, using restrictive transfusion thresholds, transfusing one unit at a time, considering furosemide to prevent transfusionassociated circulatory overload, appropriate administration of vitamin $\mathrm{K}$ for warfarin reversal, obtaining transfusion consent, managing transfusion reactions, indications for irradiated products, use of tranexamic acid, and use of a bleeding assessment tool. All respondents (100\%) indicated that they would recommend Transfusion Camp to their colleagues.

\section{Educational process objectives}

Educational process objectives were met: 1) More than $80 \%$ (range, $83 \%-94 \%$ ) of trainees rated lectures as good or excellent for all criteria evaluated; 2 ) more than $80 \%$ (range, $80 \%-98 \%$ ) agreed or strongly agreed that the seminar 
content had practical value and that the seminar content was relevant and organized. Survey response rates ranged from $26 \%$ to $57 \%$ across the 5 days.

\section{Faculty and program director feedback on transfusion camp}

A survey of program directors conducted in 2017-2018 on their perceived value of Transfusion Camp revealed that $100 \%$ of respondents ( $n=7$; four anesthesia, one hematology, one hematology pathology, one medical oncology) agreed or strongly agreed that Transfusion Camp provides a sufficient amount of information for the level of knowledge required by their residents on each of the topics addressed (Appendix S1). When asked to elaborate on improvements in their trainees' clinical practice based on knowledge imparted by Transfusion Camp, the respondents generally described increased trainee confidence in their practice.

At the end of the 2016-2017, we surveyed eight University of Toronto faculty facilitators on the change from the traditional open question seminar used in the first 3 years of Transfusion Camp (2012-2015) to the modified TBL seminars used in 2015-2016 onwards. Faculty noted increased trainee participation where either all or almost all trainees participated $(50 \%$ to $100 \%$ ); an improved quality of discussion with good or indepth discussion of the topic (62\% to $100 \%)$; improved trainee attention during the seminar where trainees were attentive, engaged, and asking questions (62\% to $100 \%$ ); and improved insight by seminar leaders into trainee knowledge so as to be able to identify gaps in knowledge and address trainee gaps (24\% to $100 \%$ ). Finally, respondents reported an overall increase in their comfort with the seminars when switching from a traditional to a TBL format (88\%-100\%).

\section{DISCUSSION}

Transfusion Camp is a longitudinal multispecialty postgraduate TM education program that has demonstrated the ability to improve TM knowledge, foster a positive attitude toward $\mathrm{TM}$, and enable a self-reported positive impact on transfusion behavior among an international group of multispecialty postgraduate medical trainees. The novel program design allows it to be efficiently provided over a large geographic area with participation by a relatively limited number of content experts. As part of a continuous quality assessment of the program, the formal knowledge assessment enabled us to determine areas where improvements are required.

Although trainees attended up to 5 days of TM education, the mean improvement in the score on the validated assessment tool was 2.7 of 20 . There may be a number of explanations for this finding. The target audience of Transfusion Camp is postgraduate trainees who are not in hematology specialties and would be expected to be at a beginner level. When it was originally developed, the validated assessment tool ${ }^{16}$ was able to distinguish between beginner (scoring, 42\%; range, 30\%-
$48 \%$ ), intermediate (62\%; range, $30 \%-87 \%$ ), and advanced (82\%; range, 61-96\%) learners. Using this scale, participation in Transfusion Camp was able to move beginner learners into the intermediate level. In the multivariate analysis, trainees with lower pretest scores had a greater improvement in scores on the posttest. Thus, while the information presented in Transfusion Camp was of benefit to trainees in all specialties, it appeared to be most effective in providing a modest improvement in knowledge for beginner trainees; it was not as effective in increasing trainee knowledge into the advanced/expert category. It should be noted that the validated assessment tool was not designed to specifically evaluate knowledge obtained in Transfusion Camp but "knowledge or skills related to TM that are absolutely essential for physicians who are not TM specialists but whose practice includes the transfusion of blood products," ${ }^{16}$ and so may not accurately reflect all of the knowledge that is gained from Transfusion Camp. Likewise, the content of Transfusion Camp was not specifically designed around the content of the assessment tool. For example, most of the material on the exam was covered on Day 1 (July) and Day 2 (September). The pos-exam was written more than 6 months later on Day 5 , demonstrating a measurable retention of the material delivered. Finally, it is notable, that even with 4 to 5 days of Transfusion Camp, the mean improvement was only 2.7 of 20 . This suggests that spending 2 hours or less of medical school training in TM, as experienced by the majority in our study and others, ${ }^{4}$ will be insufficient for preparing clinicians for transfusion practice.

The strengths of Transfusion Camp include the formal assessment of TM knowledge using a validated assessment tool. ${ }^{16}$ The tool also identified specific topics that require more focus in the curriculum. The lower scores on questions about transfusion reactions are likely because reactions are less commonly encountered or alternatively because the material may not have been delivered as effectively in the curriculum. In either case, this finding allows our group to improve future iterations of the material and to measure the effect after the change. Transfusion Camp also demonstrated significant improvement in self-rated ability in TM (Table 7), more so than the documented improvement in knowledge, and trainees endorsed behaviors that were on Transfusion Camp's list of learning objectives (Table 1). Although not objective evidence of change in behavior, an improvement in attitude toward TM alone may be beneficial for encouraging trainees to continue learning about best practices in TM in the future.

A key strength of Transfusion Camp was the interactivity of the education program. Each day consisted of a format of lectures and seminar in the morning and afternoon. This allowed ample time for discussion and in-depth review of the materials covered in the didactic sessions. Expansion of Transfusion Camp brought in individuals with specific medical education knowledge to further improve the format in which content is delivered. One significant change included the introduction of modified TBL in the seminars, which increased engagement of trainees and allowed faculty to 
recognize trainee knowledge gaps in a safe learning environment. Trainees also had exposure to local TM faculty, with the added benefit of establishing contacts for clinical $\mathrm{TM}$ advice in the future. Involving trainees from different specialties further enriched the discussion. Importantly, Transfusion Camp showed similar improvements, whether delivered locally in Toronto, remotely to other sites, or in the format in which the sessions were recorded. The potential scalability of Transfusion Camp into environments with relatively little expertise in the subject is arguably its greatest strength.

Although we did not perform a formal needs assessment at the start of Transfusion Camp, two recent studies in the literature are informative and support the current format of Transfusion Camp. ${ }^{18,19}$ Graham et al. ${ }^{18}$ used qualitative methodology with health care professionals in the United Kingdom (77\% of which were junior doctors) to determine how best to deliver TM education. The view of current education was that undergraduate education was unmemorable with theory-heavy lectures. Surprisingly, e-learning and online learning were held in low esteem, as these were inflexible to adapt to the knowledge and experience of learning. The trainees felt that the content should focus on the practicalities of transfusion (informed consent, when to prescribe blood, how to respond to transfusion reactions) and real-life scenarios. They preferred that information be delivered either in the final year of medical school or early in postgraduate training, face to face by skilled educators, preferring either simulation to "practice" or small groups modeling decisions in realistic cases. They suggested a national transfusion course that is run two to three times per year. A similar study in Australia by Flores et al. ${ }^{19}$ reported consistent messages for preferred formats including expert led face-to-face education and just-in-time short, accessible education (e.g., lanyard cards). The topics requested were practical and focused on transfusion prescribing, consent, and management of transfusion reactions. Transfusion Camp meets many of these trainee preferences and provides a portal for ongoing access to educational materials and a community of practice.

There are limitations to our assessment of Transfusion Camp. First, the validated knowledge test was developed to assess TM knowledge in first-year internal medicine trainees, ${ }^{12}$ although it was also evaluated in hematology trainees. ${ }^{20}$ We have used this validated test for a broader group of trainees from different postgraduate years and different specialties. Rasch analysis on the 2016-2017 data set, nevertheless, demonstrated a good fit. A second limitation of the validated knowledge test is that the tool does not reflect all of the material taught in Transfusion Camp, and so additional questions covering topics from Day 3 to Day 5 may be of benefit to determine the extent of knowledge being gained by learners. For future iterations, updating questions will be required to reflect changes in evidence and to improve clarity. Another possible limitation is that the same test was used before and after Transfusion Camp which could have improved scores on the posttest. To mitigate this risk, trainees were not allowed to keep the test questions, nor were they provided the answers, and there was a significant time lapse between the pretest in July and the posttest almost a year later, the following June. Feedback provided by the trainees is in the form of evaluation surveys, which are voluntary and therefore may not represent the views of all trainees. Our current methods of evaluating Transfusion Camp do not allow us to understand attendance patterns (why trainees miss certain days); why a subset of trainees do not perform well on the posttest; and why a subset of trainees do not apply learnings from Transfusion Camp. These unanswered questions form the basis of a qualitative research proposal that is under way. Ultimately, the effect of Transfusion Camp on objectively assessed, real-world transfusion behavior would be the ideal metric by which to determine educational efficacy. This has been challenging as trainees rotate through different teaching hospitals, on different rotations, and with different information technology systems. However, the international scope of Transfusion Camp now offers collaborative opportunities to tackle these questions.

Transfusion Camp is a novel approach to delivering postgraduate TM education to postgraduate trainees in multiple specialties at multiple sites. It has demonstrated a measurable improvement in TM knowledge, fostered a positive attitude toward TM among postgraduate trainees, and enabled a self-reported positive impact on behavior. Future evaluation will focus on how to further optimize the delivery of TM education and improve the translation of knowledge into transfusion practice.

\section{ACKNOWLEDGMENTS}

We thank the postgraduate trainees and faculty who participated in Transfusion Camp. We acknowledge Dr. Matthew Yan for assistance with Rasch analysis, Dr. Shuoyan Ning for her contributions to the program director survey, and the following local Transfusion Camp site administrative leads and collaborators: Dr. Alan Tinmouth, Alycia-Anne Martin, Tyra Young (University of Ottawa), Heidi Devlin (Dalhousie University), Elena Bidochka, Gina Furlong (McMaster University), Shelley Cox (Queen's University), Dr. Ed Conway, Hana Kim, Amarpreet Grewal, Mira Multinovic (University of British Columbia), Deb Quirion, Krystyna Schornagel, Chelsea Malkowich (University of Saskatchewan), Mattina Kranenburg (Western University) in Canada, and June Smith (Oxford University) in the United Kingdom. We thank Julie Sarwan and Miriam Strzinar for their local administrative support, and Robert Danielsen for audiovisual support at St. Michael's Hospital for the University of Toronto Transfusion Camp. We acknowledge Chantal Armali and Attiya Waqqas for assistance with data compilation from the University of Toronto QUEST Research Program. 


\section{CONFLICTS OF INTEREST}

YL has received research support from Novartis and Octapharma, consulting fees from Amgen, and Pfizer. AA is a consultant for Medtronic and Zoll. KP has received honoraria from Alexion and Shire and consulting fees from Ablynx, Alexion and Shire. JC has received research funding from Octapharma and Canadian Blood services. All other authors have no conflicts of interest to declare.

\section{REFERENCES}

1. Pfuntner A, Wier LM, Stocks C. Most frequent procedures performed in US hospitals, 2010. Healthcar eCost and utilization project, statistical brief \#149. Rockville (MD): Agency for Health Care Policy and Research; 2013.

2. Shehata N, Forster A, Lawrence N, et al. Changing trends in blood transfusion: an analysis of 244,013 hospitalizations. Transfusion 2014;54:2631-9.

3. Vamvakas EC, Blajchman MA. Blood still kills: six strategies to further reduce allogeneic blood transfusion-related mortality. Transfus Med Rev 2010;24:77-124.

4. Karp JK, Weston CM, King KE. Transfusion medicine in American undergraduate medical education. Transfusion 2011;51: 2470-9.

5. Strauss RG. Transfusion medicine education in medical school: only the first of successive steps to improving patient care. Transfusion 2010;50:1632-5.

6. Lin Y, Haspel RL. Transfusion medicine education for nontransfusion medicine physicians: a structured review. Vox Sang 2017;112:97-104

7. O'Brien KL, Champeaux AL, Sundell ZE, et al. Transfusion medicine knowledge in postgraduate year 1 residents. Transfusion 2010;50:1649-53.

8. Arinsburg SA, Skerrett DL, Friedman MT, et al. A survey to assess transfusion medicine education needs for clinicians. Transfus Med 2012;22:44-9; quiz 9-51.

9. Graham J, Grant-Casey J, Alston R, et al. Assessing transfusion competency in junior doctors: a retrospective cohort study. Transfusion 2014;54:128-36.

10. Kasraian L, Tavassoli A. A survey of resident physicians' knowledge concerning transfusion medicine in Shiraz, Iran. Asian J Transfus Sci 2014;8:118-20.
11. Saidenberg E, Pugh D. The use of an objective structured clinical examination to assess internal medicine residents' transfusion knowledge. Transfusion 2014;54:1537-41.

12. Haspel RL, Lin $Y$, Mallick R, et al. Internal medicine resident knowledge of transfusion medicine: results from the BESTTEST international education needs assessment. Transfusion 2015;55:1355-61.

13. Lin Y, Cserti-Gazdewich C, Callum J, et al. Evaluation of "Transfusion Camp," a postgraduate transfusion medicine education program using the BEST-TEST knowledge assessment tool. Transfusion 2015;55:2049-51.

14. Thomas PA, Kern DE, Hughes MT, et al. Curriculum development for medical education. A six-step approach. 3rd ed. Baltimore (MD): Johns Hopkins University Press; 2016.

15. Parmelee D, Michaelsen LK, Cook S, et al. Team-based learning: a practical guide: AMEE guide no. 65. Med Teach 2012;34: e275-87.

16. Haspel RL, Lin Y, Fisher P, et al. Development of a validated exam to assess physician transfusion medicine knowledge. Transfusion 2014;54:1225-30.

17. Tavakol M, Dennick R. Psychometric evaluation of a knowledge based examination using Rasch analysis: an illustrative guide: AMEE guide no. 72. Med Teach 2013;35:e838-48.

18. Graham JE, Narayan S, Pendry K. Improving transfusion education for junior doctors; exploring UKexperiences. Transfus Med 2017;27:96-104.

19. Flores CJ, Quested B, Spigiel T, et al. Junior doctors' perspectives on transfusion education in Australia. Vox Sang 2018;113: 441-8.

20. Lin Y, Tinmouth A, Mallick R, et al. BEST-TEST2: assessment of hematology trainee knowledge of transfusion medicine. Transfusion 2016;56:304-10.

\section{SUPPORTING INFORMATION}

Additional Supporting Information may be found in the online version of this article.

Appendix S1. Faculty and program director survey.

Table S1. TM education components incorporated by Canadian medical program survey respondents.

Fig. S1. Program directors' views about Transfusion Camp $(n=7)$. 